\title{
A Revolução da Longevidade: impacto na sociedade, na família e no indivíduo ${ }^{1}$
}

Ursula Lehr ${ }^{2}$

\section{Resumo}

A palestra demonstra as mudanças demográficas (alta expectativa de vida, aumento rápido do grupo das pessoas idosas), trazendo dados da Alemanha e de Singapura, analisando os impactos destas alterações da estrutura populacional para o mundo de trabalho, bem como para as relações familiares. As sociedades precisam se adaptar a um número cada vez maior de pessoas idosas, aproveitando as capacidades e potenciais deste grupo populacional e criando estruturas que atendam a necessidades específicas. A partir de um modelo de correlações entre longevidade e fatores que influenciam um envelhecimento saudável, são colocadas sugestões em nível individual, bem como elementos importantes para uma política do idoso.

Palavras-chave: longevidade; envelhecimento saudável; mudanças demográficas.

\section{Abstract}

This paper shows the demographic trends in population change (high life expectancy, increasing number of seniors) with statistics form Germany and Singapore, which analyze the effects of longevity change on the working world and on family relationships. Societies need to adjust to an increasing number of older people by profiting from the expertise and the potentials of this part of the population and by creating structures to attend to their specific needs. A model of interacting influences on longevity points out suggestions for the individual on how to get older in a healthy way, and important elements for a policy for the aged are also shown.

Key words: longevity; psycho-physical well-being; demographie trends.

\footnotetext{
${ }^{1}$ Palestra apresentada no Pré-Congresso do Congresso Mundial da International Association of Gerontology, Singapura, 17 de agosto de 1997. Tradução Marli Rosa MacFarlane e revisão de bhannes Doll.

${ }^{2}$ Profa. Dra. Dra. Honoris Causa, Diretora do Centro Alemão de Pesquisa sobre o Envelhecimento, Universidade de Heidelberg/Alemanha.
} 


\section{Introdução}

Estamos vivendo num mundo que está ficando grisalho. Jamais, em todos os tempos, tantos indivíduos podiam atingir uma idade tão avançada. A expectativa de vida aumentou enormemente em todos os países europeus, bem como em todos os países do mundo. Há também uma diminuição no índice de natalidade. Deve-se isto à melhoria das condições sócio-econômicas de vida e ao progresso da medicina moderna - e é também influenciada pelo estilo de vida.

Contudo, não é somente importante acrescentar anos à vida, mas também acrescentar vida aos anos. Muitos anos atrás, Hans Schaefer, o renomado especialista em medicina social e professor desta Universidade de Heidelberg, afirmou: "Nossa expectativa de vida depende do nosso estilo de vida. Expectativa de vida não significa somente tempo de vida mas também qualidade de vida; não leva em consideração somente a idade que um indivíduo terá, mas como ele envelhecerá." (Schaefer, 1975).

A transformação demográfica é um desafio para cada um de nós, para a sociedade, a economia, a política e as ciências, bem como para a família e o indivíduo.

\section{Tendências demográficas na modificação da população e suas consequências}

Os aspectos relevantes na transformação da população da Alemanha, que devem ser enfatizados, são apresentados sob os seguintes seis aspectos:

\section{O aumento da expectativa de vida do indivíduo}

A expectativa de vida de uma criança recém-nascida na Europa era de 45 anos há cem anos atrás; hoje, na Alemanha, é de 727para os homens e de 79,2para as mulheres. Em Singapura, é de 74,1 para os homens e de 78,4 para as mulheres.

Hoje as mulheres de 60 anos, na Alemanha, podem esperar viver mais 23 anos; um homem de 60 anos, 19 anos mais. Isto quer dizer que, após a aposentadoria, um indivíduo viverá cerca de 20 anos mais - um quarto de sua vida! 


\section{A população que está envelhecendo}

Estamos vivendo num mundo que "está ficando grisalho". Há cem anos atrás, o percentual de pessoas com 60 anos de idade ou mais velhas, na Alemanha, era de $5 \%$, hoje é de $21 \%$ e, em Singapura, 9\%; no ano 2000 será de $26 \%$ na Alemanha e de 11\% em Singapura; em 2030, quando os estudantes de hoje forem indivíduos aposentados, cerca de $37 \%$ de toda a população da Alemanha terá 60 anos de idade ou mais e, em Singapura, 26\%.

Também houve um aumento no grupo de indivíduos com 70, 80, 90 e 100 anos de idade. Há 25 anos atrás, tínhamos somente 385 centenários em nosso país; em 1994, nosso Presidente congratulou 4602 pessoas que completaram 100 anos ou mais. Foram 582 homens e 4020 mulheres. Para o ano 2000, espera-se que mais de 10.000indivíduos atinjam o centenário. Cientistas de todas as disciplinas e Faculdades, administradores e políticos também terão de discutir a questão da longevidade combinada com o nível de bem-estar psico-físico. O que pode ser feito para assegurar um envelhecimento saudável? $\mathrm{O}$ que pode ser feito para assegurar qualidade de vida na velhice?

\section{A proporção entre os diferentes grupos etários}

Há cem anos atrás, a proporção de indivíduos com idade acima e abaixo de 75 anos no nosso país era de 1:79, em 1925, o índice era de 1:67; em 1936, 1:45; em 1950, 1:35; em 1970, 1:25, em 1994, 1: 14,8 e, no ano 2000, será de 87; em 2040, 162

Tivemos também uma enorme diminuição no índice de natalidade em todos os países da Europa. A Irlanda tem o índice mais alto de fertilidade, com 1,87, a Itália e a Espanha, o mais baixo, com 1, 17 e 1, 18, seguidos pela Alemanha com um índice de fertilidade de 1,24 Singapura também apresentou uma diminuição no índice de natalidade. Foi muito bem sucedida na sua política anti-natal de 1965-1987. Como resultado da política "pare no segundo", o índice total de fertilidade caiu de $3,08 \mathrm{em} 1970$ para 20. Em seguida, vem a Tailândia com 2,6 a Indonésia com 33, a Malásia com 3,6e as Filipinas com 4,3 (Teo, 1996 p.270). 


\section{A estrutura dos lares}

Existe uma forte tendência de se passar do lar com três gerações para o com duas e para o com uma geração - e daqui para o lar com uma só pessoa. Somente 1, 1\% de todos os lares na Alemanha tem as três gerações presentes.

De todos os indivíduos com 65 anos de idade ou mais, quase 40\% vivem em lar de uma só pessoa - 63\% das mulheres com 75 anos de idade ou mais vivem sós. Em Singapura, 85\% dos idosos vivem com suas famílias e somente $2 \%$ em lares de uma só pessoa. A estrutura e o tamanho do lar de um idoso é muito diferente. Em Singapura 17, 1\% dos idosos moram em lares de uma e duas pessoas; na Alemanha, 86,4\%. 82,9\% dos singapureanos vivem em lares com três ou mais pessoas, enquanto que na Alemanha somente 13,8\%. Talvez isto também se modifique. Deve-se ter em mente, no entanto, que, de acordo com muitos estudos realizados em diversos países da Europa, esta mudança na estrutura do lar não deve ser identificada como isolamento do idoso, visto terem sido reportados contatos freqüentes de integração, independentemente da estrutura do lar.

Na Alemanha, 4\% da população com 60 anos de idade ou mais, vivem em asilos ou lares para idosos; em Singapura 1,6\%.

Uma preocupação muito séria quanto à transformação demográfíca em Singapura é o problema de acomodação. No futuro, as acomodações para os idosos viverem junto com seus filhos, serão reduzidas; aumentarão os lares de duas e uma pessoas. Conseqüentemente, serão necessários mais serviços que atendam aos idosos em casa.

O resultado da combinação família de tamanho menor e aumento da força de mão-de-obra feminina, e o aumento da longevidade (talvez com duas gerações em idade de aposentadoria), significa que a família pode enfrentar dificuldades de ser uma importante instituição social para o cuidado dos idosos. Por outro lado, existe um estudo feito em Singapura (Mehta, Osman; Lee, 1995) que mostra que morar junto com a família foi o preferido por todos os respondentes e que este ainda era o tipo predominante de acomodação para muitos idosos (veja Teo, 1996 p. 274). 


\section{Da família de três gerações para a família de quatro ou cinco gerações}

Antigamente, uma criança recém-nascida raramente tinha a oportunidade de conhecer seus quatro avós. Hoje, com muita freqüência, a criança chega a conhecer todos os seus quatro avós e até mesmo dois ou três de seus bisavós. É muito comum pessoas na casa dos 60 com bisnetos e, também, pessoas nos seus 60 ou mais, que estejam cuidando de seus pais (cerca de 20\%). Devido a isto, desde há alguns anos atrás, os gerontólogos estão enfatizando o fato de que discussões sobre as famílias de três gerações (não mais lares!) não são mais tão relevantes para a situação demográfica contemporânea, visto haver um notável aumento no número de famílias de quatro (e cinco) gerações.

Mesmo que a maioria das pessoas idosas ainda estejam ativas e competentes, as modificações na estrutura do lar e da família devem ser lembradas sempre que se discutirem problemas relacionados com o cuidado de idosos.

Isto significa que com muita freqüência, avós cuidam de membros ainda mais velhos na família.

\section{Do contrato de três gerações para o contrato de cinco gerações}

A idéia de um contrato de três gerações é que as pessoas que ainda estão na força de trabalho têm de sustentar (via contribuições de seguro e impostos) aqueles indivíduos que ainda não estão trabalhando bem como aqueles que já encerraram sua etapa de trabalho e se aposentaram. Lá pelo início deste século, os indivíduos de 15 a 70 anos de idade trabalhavam para sustentar os com menos de $15 \mathrm{e}$ mais de 70 anos dessa maneira. Mas, nessa época, somente $2 \%$ da população tinha 70 anos ou mais. Hoje, os indivíduos de 25até 58/ 60anos, que estão na força de trabalho, sustentam aqueles que ainda não estão trabalhando (que, em alguns casos, são de duas gerações, porque alguns estudantes de 30 anos têm os seus próprios filhos ainda pequenos), e aqueles que já não trabalham mais - e estes são $25 \%$ da população, freqüentemente duas gerações. Isto afeta o nosso sistema de pagamento de aposentadorias. 
Atualmente a situação econômica do idoso no nosso país ainda está boa. Somente 1,5\% dos indivíduos com 60anos ou mais, vivem abaixo da linha de pobreza (na maioria mulheres com 75 anos e acima) e necessitam apoio do sistema de previdência social (dos 3,9\% dos idosos que vivem em lares para idosos, quase $70 \%$, precisam do apoio da previdência social).

É bastante incomum em nosso país que os filhos adultos dêem apoio financeiro e material a seus pais. Muito freqüentemente os pais idosos e avós sustentam seus filhos e netos com a aposentadoria que recebem. Ouvi dizer que em Singapura somente 8,3 dos homens e 6,2\% das mulheres não receberam nenhum apoio financeiro de seus filhos. A contribuiçâo financeira vem dos filhos, mesmo nos casos de não cohabitarem. 84\% das pessoas idosas recebem apoio material e financeiro dos membros mais próximos da família e de outros parentes (Teo, 1996 p.275). Mas o que acontecerá quando, devido à revolução da longevidade, as duas próximas gerações em idade de aposentadoria tiverem de ser sustentadas e cuidadas?

\section{Possíveis efeitos das mudanças na longevidade, no mundo do trabalho}

A idade oficial para aposentadoria na Alemanha é de 63 anos e em breve será de 65. Contudo, a maioria dos empregados, hoje em dia, se aposentam entre os 58 ou 59 anos de idade. Isto quer dizer que eles ainda terão mais um quarto do tempo de suas vidas quando pararem de trabalhar, e muitos deles ainda em ótima saúde. Estes indivíduos estão iniciando uma nova fase da vida, a assim chamada "liberdade tardia", com muitas atividades de lazer.

Em Singapura, a idade de aposentadoria, 55 anos, era muito cedo; desde 1988, subiu para 60 anos - e, que eu saiba, estão pensando em estendê-la para 65. Isto terá efeitos positivos não somente para a situação econômica do idoso mas para a sua imagem. Peggy Teo (1996) afirmou: "Em termos de contribuição financeira, os indivíduos com 60 anos ou mais são vistos pelo Estado como uma carga para os singapureanos." (p.272). Isto mudará quando o idoso se tornar economicamente mais ativo. 
Por outro lado, com muita freqüência os empregadores não querem manter o empregado. As mudanças tecnológicas rápidas tornam os trabalhadores mais velhos em grupo problema. É necessário que os trabalhadores mais velhos possam atualizar as suas habilidades e também adquirir outras. "Aprendizagem durante toda a Vida" ou "educação continuada" é uma necessidade num mundo em transformação. Afim de fazer com que os trabalhadores permaneçam na força de trabalho, foi introduzido o trabalho em meio turno e o de horário flexível e programas de retreinamento com o objetivo de melhorar a produtividade do trabalhador mais velho. No entanto, isto é melhor possível se ele tiver nível mais alto de escolaridade e estiver acostumado a aprender.

Há um problema para os idosos de hoje, não para os de amanhã. Os dados do censo de 1990 mostraram que a maioria das pessoas de idade em Singapura $(81,8 \%)$ não tinha nenhuma escolaridade formal ou não tinham completado a escola primária. Na Alemanha, onde a educação compulsória foi introduzida na metade do século passado, os idosos têm escolaridade formal; contudo, 12\% têm menos de oito anos de escolaridade - a maioria somente seis ou sete anos (Höhn, 1994, p. 121). Mas isto também está mudando. Todos os idosos de amanhã em Singapura, bem como em nosso país, terão uma escolaridade formal bem melhor.

Contudo, temos de discutir este tópico não só do ponto de vista do indivíduo; deve-se também discutir por quanto tempo a indústria poderá viver sem a experiência técnica e as habilidades especiais dos empregados idosos. No que diz respeito à transformação demográfica, os empregadores devem preparar-se para absorver indivíduos de 60 anos ou mais, desde que tenham condições e queiram trabalhar.

No futuro estaremos vivendo num "mundo industrial que está se tornando grisalho” (Stanger, 1985; Sterns; Alexander, 1987). Em 1989, na Europa, 44,6\% dos indivíduos ativos no trabalho, tinham mais de 40 anos de idade; esta proporção aumentará consideravelmente. Em 2010 a percentagem de indivíduos com menos de 30 anos ainda será de 2325\%; os com mais de 50 anos aumentará para 26\% (Bäcker; Naegele, 1993). Este processo 
continuará até 2030. Supõe-se que, então, um terço da população ativa será de indivíduos com mais idade, enquanto que somente um quinto será de jovens.

Devido à situação demográfica, os desenvolvimentos no mercado de mão-de-obra após o milênio (2010, 2020), dão motivo para que se espere um declínio na força de trabalho em potencial, de modo que existem planos para aumentar a idade de aposentadoria, da atual idade oficial de 63 para 65 anos, na Alemanha (a partir de 2001). Isto faz com que surja uma situação paradoxal que, embora hoje ainda haja uma falta de empregos e o nível de desemprego seja alto (mais de 4 millhões), haverá, no entanto, uma falta de trabalhadores no futuro. Haverá então, uma demanda cada vez maior de trabalhadores mais velhos. Esta tendência trará diversas conseqüências à economia e ao mercado de trabalho. Pode-se esperar conseqüências na área de qualificação e treinamento. Visto que será mais difícil para as empresas continuarem o que ainda é uma prática comum, isto é, recrutar indivíduos mais jovens, melhor qualificados (e mais baratos), um maior treinamento para os trabalhadores de mais idade se tornará cada vez mais importante. Suponhamos que o conhecimento que hoje é novo estará desatualizado daqui a dez anos, o treinamento de indivíduos de 50 ou 55 anos de idade provará ser tão frutífero quanto ao oferecido aos indivíduos de 20 anos (Johnson, 1993).

A imagem negativa do atual trabalhador mais velho precisa mudar; o preconceito deve dar lugar a uma avaliação realista da habilidade ocupacional que, na maioria das áreas, não se deteriora com o aumento da idade.

É necessária uma maior flexibilidade - não só flexibilidade em horário de trabalho, mas também uma abordagem flexível quanto ao fim da vida ativa e a transição para a fase de aposentadoria. Qualquer idade fixa para aposentadoria baseiase na suposição de que haja um declínio geral no desempenho e nas habilidades. No entanto, isto contradiz as descobertas científicas que, há muito tempo atrás, desacreditavam o conceito de deficiências causadas pela idade e mostravam que há 
diferenças consideráveis entre os indivíduos em processo de envelhecimento. Temos de aprender muito mais sobre a competência e os potenciais especiais de muitos indivíduos da geração mais velha.

Há muitos tipos de flexibilidade que podem ser considerados. Já em 1972 Hearnshaw sugeriu introduzir "licenças-prêmio periódicas", isto é, anos sem trabalho, ou períodos intercalados a cada seis ou sete anos, dentro do período de participação ativa na força de trabalho. Períodos para estudar mais, treinar e desenvolver novas atividades de lazer.

Outras possibilidades são a "aposentadoria gradual", " aposentadoria parcial" ou a "pensão parcial”, embora sejam pouco comuns na Alemanha. Esses modelos, que têm sido utilizados com sucesso na Escandinávia, Canadá e Estados Unidos, permite que os trabalhadores mais velhos decidam, eles mesmos, a redução do horário de trabalho. O "plano de aposentadoria parcial seletiva" (SEPR) nos Estados Unidos permite uma redução na carga horária a partir dos 55 anos, porém, sem uma idade teto, limite e fixa, de modo que até mesmo os indivíduos de 70 anos ainda podem trabalhar dez horas por semana, por exemplo, recebendo 25\% do salário e 75\% da pensão. Psicologicamente, esta é uma solução desejada por muitos indivíduos: os trabalhadores mais velhos permanecem ativos sem se estressarem. O trabalho os estimula e desafia, usam suas habilidades e assim as estão exercitando, mantêm seus contatos sociais e têm uma rotina semanal e diária estruturada.

\section{Longevidade e relacionamentos familiares}

Como foi mencionado anteriormente, a família está se modificando. É necessário ver a família como uma entidade inteira.

1. O relacionamento familiar na velhice e a relevância da família para o idoso bem como a do idoso para a família deveriam ser discutidos no referencial da família durante todo o tempo de vida. 
2 A família - consistindo de pai, mãe e filhos (dependentes) - é muito freqüentemente vista como uma entidade estática ao invés de um processo dinâmico de expectativa de troca de papéis de todos os membros da família. É necessário ver a família como um processo dinâmico de interação durante toda a vida: o desenvolvimento e as modificações de um membro da família causa desenvolvimento e modificações em todos os outros membros da família. Somente uma tal visão de processos de desenvolvimento na família tornará possível a inclusão do idoso de uma forma adequada.

3As políticas familiares, na maioria dos países europeus, estão direcionadas somente para sistemas de apoio a bebês, crianças e adolescentes. Com freqüência, os estágios mais avançados do ciclo de vida familiar, bem como o cuidado com os outros membros da família (pais e mães) são negligenciados. Isto não é válido para Singapura, onde os pais idosos estão integrados.

Também a visão científica sobre a família teve como foco, durante muito tempo, a criança e a influência mãe no seu desenvolvimento. Mais recentemente, também tem sido estudada a influência do pai sobre o desenvolvimento da criança. Durante os últimos anos, também foi dada atenção à influência dos filhos sobre o desenvolvimento dos pais. No entanto, os indivíduos de 50/60 anos de idade ou mais, não foram considerados nas pesquisas sobre o desenvolvimento da família e política familiar.

4 Desde o início da década de sessenta, dentro da sociologia da família, tem havido um interesse cada vez maior nos idosos. Os estudos chegaram a um acordo geral de que relacionamentos familiares harmoniosos estão relacionados ao bem-estar psicológico do idoso. Além disso, todos concordam que a interação dentro das famílias não diminui com o aumento da idade. Há troca de papéis, mas não necessariamente perdas de desempenho de papéis familiares.

Uma afirmativa geral de vida de que "o meio ambiente natural para o idoso é dentro da família” não pode ser apoiada pelo resultado das pesquisas feitas nos países europeus. "Intimidade 
com distância" é a fórmula que define o estilo de vida ótimo para os idosos, não os lares com três gerações. Aqui também existem diferenças entre os nossos países.

5A política familiar, que negligenciou o idoso durante muito tempo, está agora, dando mais atenção aos mais velhos desde o momento em que os economistas e legisladores decidiram sugerir "cuidado em família" como a melhor maneira e a mais barata, de cuidar dos idosos frágeis e dependentes. Enquanto que é verdade que o cuidado das famílias para com seus idosos, mantendo-os fora de asilos, deva ser apoiado pelas sociedades, é problemático elogiar este tipo de cuidado-familiar como a única e melhor solução. Oitenta e três por cento (83\%) dos idosos frágeis em nosso país são cuidados pelos membros da família, 18\% por enfermeiros profissionais e pelo serviço social.

Nossa pesquisa empírica sobre os relacionamentos entre filhas idosas e pais idosos mostrou que o conflito e o estresse têm como causa muitas situações do passado e do presente. Fatores biográficos estão influenciando muito a interação.

6 Deve-se, no entanto, evitar ver o idoso como um objeto doente a ser cuidado e que é dependente de sua família. Os papéis a serem desempenhados na família na velhice não são definidos somente pelo receber ajuda mas também por dar ajuda. Esta ajuda é oferecida não somente para a geração acima - freqüentemente bisavós -, mas é também oferecida aos filhos e netos adultos. Os avós são muitas vezes vistos como a geração "sanduíche".

7Também existem muitos papéis inter-familiares na velhice e seria errado vê-los como um substituto para a participação extrafamiliar inexistente. Nossos estudos mostram: contatos sociais extra-familiares podem produzir uma quantidade menor, mas de qualidade melhor, de contatos interfamiliares. Nestes casos, há um grau mais alto de satisfação de vida. A falta de participação social extra-familiar correlaciona-se com uma quantidade maior, mas de qualidade menor, de contatos familiares e com menos satisfação de vida. 
8 A necessidade de um maior contato familiar com os filhos, é expressa com mais freqüência por aqueles idosos:

- que têm algum problema no papel de esposo(a) (especialmente nas mulheres);

- ou que tenham perdido seus parceiros (viuvez);

- que têm saúde mais precária e são dependentes físicos;

- que têm dificuldades econômicas;

- que têm falta de participação extra-familiar;

- que têm interesses restritos e baixo grau de atividade mental;

- e nas mulheres idosas, que viveram toda a vida somente para a sua família e seus filhos, e que não encontraram nenhum outro sentido para as suas vidas.

Ter os filhos como o foco das atenções está muitas vezes relacionado a uma percepção negativa da idade ou a situações de vida que são definidas por privações e estresse. Não se deve ver este tipo de extrema centralização na família, na velhice, como normal e nem como ideal.

9A necessidade de maiores contatos familiares com os pais idosos se dá principalmente em situações-problema dos filhos (como problemas de saúde ou econômicos, ou necessidade de auxílio no trabalho da casa). O relacionamento com os próprios pais é freqüentemente visto mais como uma fonte de conflito durante todo o ciclo de vida do que o relacionamento com seus próprios filhos.

10 A participação interfamiliar é vista de uma maneira muito positiva e gratificante e que contribui para a "qualidade de vida" na velhice se estiver baseada em interesses comuns e estímulos e enriquecimento mútuos, ao invés de numa dependência mútua. Muito freqüentemente a fonte deste estímulo e enriquecimento mútuos está na participação extra- familiar, a qual deveria ser cultivada durante toda a vida.

11 Um alto grau de centralização na família (como é sugerido nas expectativas do papel tradicional) causa problemas de adaptação, especialmente para as mulheres, navelhice. Também podemos afirmar que, para os homens, a extrema centralização no trabalho causa problemas de ajuste na velhice: freqüentemente ele se torna totalmente dependente da pessoa que toma conta da casa. 
O que é necessário é uma política familiar que olhe para todos os membros da família sob uma perspectiva que abranja toda a vida, que estimule nas mulheres, quando ainda jovens, uma orientação extra-familiar e, nos homens, uma orientação mais interfamiliar. Somente assim será estabelecida uma relação que não esteja baseada em dependência mútua, mas num alto grau de comunidade, em interesses e tarefas mútuas. Tal relacionamento será decisivo para uma satisfação de vida na velhice.

12 A participação social extra-familiar, bem como a interfamiliar, são necessárias para a qualidade de vida na velhice. Interesses e contatos sociais dentro e fora da família não devem ser vistos como funções compensatórias ou como substitutos. Os interesses e a participação extra-familiar e interfamiliar devem ser vistos como um complemento necessário ou um suplemento para esposos e esposas, pais e filhos, durante todo o seu ciclo de vida.

\section{Longevidade e a terceira idade hoje e no futuro}

O início da "Terceira Idade" coincide com a aposentadoria; de modo que hoje cerca de $26 \%$ da população alemã vive dentro deste período da vida. Quando o período de trabalho termina e a "Terceira Idade" inicia, pode-se ainda esperar mais um quarto de tempo de vida.

Em comparação com o passado, a terceira idade hoje e amanhã é determinada por:

- melhores condições de saúde, maior consciência da necessidade de prevenção e esforços para uma "vida saudável"; - mais segurança econômica devido a carreiras mais qualificadas, também para as mulheres;

- menor grau de integração dentro da família, aumentando a singularização;

- menor grau de "ser necessário" na família, no emprego e na sociedade;

- alto grau de diversidade de interesses nas horas de lazer;

- um estereótipo mais negativo do idoso na nossa sociedade, que nega a competência do idoso e exige um "rejuve- 
nescimento" como a cura para tudo (isto pode ser encontrado na política e na indústria);

- baixo grau de aceitação de programas especiais para idosos, tais como viagens para idosos, refeições especiais para idosos, etc. Os idosos querem ser integrados e não segregados;

- ansiedade quanto ao fato de estarem sendo cuidados; a maioria das pessoas de idade não querem ser ajudadas;

- ansiedade pelo fato de estarem ficando dependentes, o que não coincide com a real prevalência da dependência.

Para alguns indivíduos o início da "Terceira Idade" significa uma transição muito difícil que pode elicitar uma crise se o indivíduo não estiver preparado para ela e não tiver antecipado esta situação. Quarenta e cinco anos atrás, os médicos referiam-se ao " choque da aposentadoria" (Pensionierungs-Schock) ou mesmo à "morte devido à aposentadoria" (Pensionstod) a medida em que prevalecia o aumento rápido das doenças após a aposentadoria. Muitos indivíduos sentem que não são mais necessários, que estão sendo empurrados para uma posição marginal na sociedade.

Estas reações são menos freqüentes hoje em dia. Os tempos mudaram. Hoje, a maioria dos indivíduos vêem a aposentadoria com sentimentos positivos e anseiam por ela; dão boas-vindas à "liberdade tardia", têm muitos planos diferentes e querem aproveitar as coisas que não puderam alcançar devido ao envolvimento com o trabalho e compromissos com a família.

Temos de fazer tudo para um envelhecimento saudável.

Novas necessidades e novas oportunidades: um desafio para a indústria

Em especial, deve-se enfatizar que a "Terceira Idade" não coincide com o período de dependência física, dependência total ou inutilidade.

Entre as necessidades de um grande grupo de indivíduos idosos, está a exigência de oportunidades de serem incluídos nas 
decisões a respeito da sociedade e de sua vida diária. Os indivíduos da "Terceira Idade" não desejam ser desligados e serem rotulados como objetos de cuidado somente!

A maior parte das necessidades da "Terceira Idade" na Europa e Estados Unidos são orientadas para como passar as horas de lazer; os interesses dos idosos são direcionados basicamente para atividades físicas e culturais. As viagens fazem parte dos planos mais freqüentemente mencionados para um futuro próximo, visto que a situação econômica da maioria deles pode ser vista como favorável. Mais de 50\% dos indivíduos com mais de 60 anos têm sua própria casa ou apartamento; as cadernetas de poupança daqueles com mais de 65 anos é maior que a de qualquer outro grupo etário. Muitos indivíduos aposentados são mais ricos hoje do que antes. Contudo, não se deve esquecer que um pequeno grupo, especialmente de mulheres com mais de 75 anos, vive em estado de pobreza.

As oportunidades de atividades para as horas de lazer para os que estão com boa saúde e fisicamente em forma, - e isto é verdade para $8090 \%$ da faixa etária dos 6086 , e para $60-70 \%$ dos com mais de 85 anos de idade, - deveriam ser mais amplas de modo a ir ao encontro das diversas necessidades e aspirações. Envelhecimento não significa homogeinização; “o idoso" não existe! Não existe "o idoso", não existem "normas de idade", mas existem muitas variações, existem os mais diferentes "padrões de envelhecimento".

Tendo em vista que formas específicas de envelhecimento resultam de experiências ao longo da vida, o idoso de amanhã terá outras necessidades e prioridades que o de hoje. "A maioria deles está acostumada a um padrão de vida mais alto, melhor moradia e outros hábitos de consumo. Freqüentaram a escola por mais tempo, na maioria das vezes tiveram uma educação vocacional ou universitária: a maior parte das mulheres se juntou à força de trabalho. Espera-se que a saúde dos próximos jovens velhos seja, em média, melhor que a de seus predecessores." (Friis, 1991)

No entanto, ainda existem algumas tendências que devem ser observadas em grupos mais ou menos grandes de indivíduos idosos atuais: 
Uma tendência crescente à singularização pode ser observada na nossa sociedade devido a um número cada vez menor de casamentos, números crescentes de divórcios, e viuvez. Isto significa que os programas devem ser mais direcionados a indivíduos sós ao invés de para famílias. Isto é válido para alimentação e artigos de uso diário, mas também para reuniões, viagens e programas culturais (que deveriam também incluir atividades sociais).

A singularização também implica em se ver as instituições de auto-ajuda em situações difíceis, como muito valiosas. Conseqüentemente, a vontade de participar de organizações voluntárias ou de prestação de serviços, está presente em muitos indivíduos idosos.

O desejo de fazer algo que seja bom para a própria saúde prevalece num grande grupo de indivíduos idosos. Num estudo realizado em $1992,87 \%$ dos idosos expressaram o desejo de "permanecer em forma física e mentalmente" (primeiro lugar), comparado com $79 \%$ que estavam preocupados com a segurança econômica e social (segundo lugar).

Muitos indivíduos idosos estão prontos a participar de programas de prevenção, desde que sejam planejados de forma atraente. É desejável encorajar as curas em spas, mesmo que tenham de ser pagos pelos próprios idosos. Em especial, os programas de condicionamento físico nos spas, se planejados de forma atraente, serão aceitos pela maioria dos idosos. Estes programas podem enfatizar atividades físicas ou mentais/culturais e/ou podem ajudar a aumentar a interação social. Outras maneiras de atrair os idosos consistem em grupos de discussão, para refletir sobre eventos na vida do grupo etário, sobre tópicos tais como aposentadoria, situação do ninho vazio, restrições devido a limitações físicas, viuvez, etc. e compartilhar opiniões sobre como enfrentar estes eventos.

Fora alguns tipos de "Lebenshilfe" (orientação prática) o objetivo deve ser definido pela manutenção e recuperação do preparo mental e físico. Os programas de treinamento mental podem ir desde palavras cruzadas até corrida cerebral (brain jogging), de cursos de línguas estrangeiras em pequenos grupos ou por auto- 
instrução com fitas, até outros conteúdos. Também podem consistir em cursos de preparação para excursões educativas.

As outras necessidades de muitos indivíduos idosos diz respeito a auto-imagem positiva. Eles não querem fazer algo somente para a sua saúde, mas também para a sua aparência, de modo que possam aceitá-la. Um mercado de vestuário confortável, mas moderno e elegante; sapatos elegantes mas adequados, cosméticos para a pele e cabelos são importantes. Programas de orientação que também incluam problemas de nutrição são muito apreciados.

\section{Ajuda para a vida diária na velhice}

Mesmo que possamos supor que a maioria dos indivíduos da "Terceira Idade" esteja em boas condições físicas e mentais, existem algumas limitações restritas dessas condições, que podem tornar a vida diária complicada, mesmo para os pensionistas ativos. Mesmo os indivíduos mais jovens, quando machucam uma mão ou quebram um braço, têm consciência da dificuldade em abrir uma garrafa de água mineral, em tirar a tampa de um vidro de geléia, abrir uma lata ou uma garrafa de vinho, só para mencionar alguns exemplos. Existem muitos dispositivos que podem auxiliar a superar estes problemas diários. Ainda tem espaço para novas iniciativas industriais, inspirações criativas e novos designs.

Um outro exemplo se refere às tampas dos vidros de medicamentos e a aplicação de mini drágeas, que às vezes têm de ser partidas ao meio ou em quatro! Ou tente abrir com dedos com reumatismo (que normalmente não torna ninguém dependente) a fechadura da porta de sua casa ou girar a chave de um armário. Tente ajustar os botões de seu fogão elétrico. Ou ajustar a torneira do banheiro para a temperatura exata. E que tal enfiar uma agulha para costurar? Como deveriam ser planejados os telefones a fim de serem usados também por dedos com algum problema? E por que tantos aparelhos auditivos são deixados sem uso sobre a mesa de cabeceira? Existem tantas coisas importantes para a vida diária que podem e deveriam ser melhoradas. Deve-se dar mais atenção a estes aspectos de leve dependência física, pois 
interferem no desenvolvimento e levam à dependência total. Deveriam estar incluídos entre os principais temas de prevenção e geroprofilaxia!

A lista de auxílios para a vida diária na assistência à velhice, em casos de deficiências de menor importância nas habilidades motoras e sensoriais, poderia ser maior. Imagine só a dificuldade em movimentar as persianas das janelas ou pegar a louça e panelas na prateleira bem de baixo de seu armário de cozinha. E, só para mencionar uma outra área de desafios diários: o que poderia ser feito para tornar mais fácil dirigir na "Terceira Idade" ? Como a tampa do tanque de gasolina poderia ser melhorada, e como os postos de gasolina poderiam se adaptar facilmente aos indivíduos idosos?

Por que os 'walk-man' têm somente um design para jovens e não são equipados com algum pequeno dispositivo extra para ser usado por dedos menos flexíveis? A indústria tem de fazer muitos esforços para adaptar seus produtos para a transformação demográfica, a fim de entrar no espaço de vida e na qualidade de vida de um quarto do período médio de vida dos indivíduos!

Deve-se lembrar que o ambiente físico, o meio ambiente, normalmente não interfere no comportamento de indivíduos capazes. No entanto, com a diminuição do preparo físico, o meio ambiente passa a determinar o comportamento dos indivíduos. O meio ambiente físico pode contribuir para a dependência e restrição do espaço de vida (o que pode levar a uma diminuição do preparo físico e mental) ou pode ser favorável e adaptável, estimulando atividades e aumentando as competências existentes assim como os recursos pessoais.

Estas afirmações são ainda mais verdadeiras para indivíduos dependentes ou incapacitados. Mesmo não superestimando a sua predominância, tudo deveria ser feito para procurar novas possibilidades e desenvolvimentos a fim de tomar a vida mais fácil para essas pessoas, e também para aqueles que os estão cuidando.

\section{Ajuda para os indivíduos dependentes ou incapacitados}

Um estudo representativo de INFRATEST (1992) sobre a prevalência da dependência na velhice mostra que o envelhecimento não é, de modo algum o mesmo que ficar dependente. Na 
faixa etária dos 6074 anos, somente 34\% são dependentes e precisam de uma maior ou menor ajuda. Na faixa etária dos 75-85 anos somente $10 \%$ são dependentes - indicando que $90 \%$ deste grupo são totalmente capazes de enfrentar os desafios diários. Somente no grupo dos de 85 anos para cima, 21\% dos homens e $28 \%$ das mulheres, foram avaliados como sendo dependentes. Em outras palavras: $79 \%$ dos homens e $72 \%$ das mulheres de 85 anos ou mais são capazes e independentes na sua vida diária.

Este estudo INFRATEST também mostra que uma grande proporção de indivíduos dependentes precisa da ajuda de outros, simplesmente porque a situação na sua casa e na vizinhança era desfavorável, visto não terem elevadores; era difícil de manter o apartamento limpo ou aquecido, ou, ainda, muito longe de um supermercado. Aqui as condições ambientais têm de ser modificadas!

Novos mercados serão abertos no setor "para o cuidado de idosos dependentes”. Estes serão mercados na área de prevenção primária, secundária e terciária, ou na de reabilitação, e, finalmente, mercados para indivíduos cuja dependência não pode ser revertida e que tenham de aprender a lidar com as restrições e incapacidades. Deve-se esclarecer aqui aquilo que pode contribuir para o alívio de sua situação e para a promoção da qualidade de vida do indivíduo dependente e daqueles que os estão cuidando.

Tanto para os médicos como para as pessoas que cuidam do idoso, é necessário um sólido treinamento geriátrico, incluindo informações sobre o "envelhecimento normal" (i.e. Gerontologia e não somente geriatria).

Os próprios profissionais de enfermagem precisam de ajuda e aconselhamento a fim de suportarem a difícil tarefa e evitar o efeito "burn-out" (esgotamento). Em nenhum outro lugar a rotatividade de pessoal é tão grande quanto no setor de profissionais de enfermagem, especialmente daqueles que cuidam de idosos. Da mesma forma, os membros da família que cuidam de um pai, mãe ou outro parente dependente, precisam de orientação, assistência e ajuda especial (por exemplo, a fim de evitar o aumento no número de casos de "maus tratos ao idoso"). 
Além do mais, existem muitos auxílios técnicos que aumentam a independência do paciente, pelo menos em algumas áreas, e, conseqüentemente, torna mais fácil o trabalho do profissional de enfermagem. Por exemplo, camas com altura ajustável, colchões anti-cúbito, colchões d'água, elevadores hidráulicos que auxiliam no levantar-se, chuveiros adaptados para os incapacitados fisicamente, levantadores para banheiras, ou sistemas de chamadas de emergência.

Em nenhum caso se deve reforçar a imagem negativa de idoso na nossa sociedade. Mais uma vez, deve-se enfatizar: longevidade, envelhecer, não quer dizer ficar dependente. Devemos lembrar das recomendações do Plano de Ação de Viena, que a Assembléia Mundial do Idoso aprovou unanimemente em 1982 e que foi aceito pelas 140nações da Assembléia Mundial das Nações Unidas:

"Legisladores e pesquisadores, bem como a mídia de massas e o público em geral talvez precisem de uma mudança geral de perspectiva afim de verem que o problema do envelhecimento, hoje em dia, não é simplesmente o de fornecer proteção e cuidado, mas o de envolvimento e participação dos idosos e dos que estão envelhecendo. Eventualmente, a transição para uma visão positiva, ativa e orientada de modo a desenvolver o processo de envelhecimento, poderá muito bem resultar da ação dos próprios idosos, através da simples força se seu número crescente e sua influência. A conscientização coletiva de ser idoso, como um conceito socialmente unificador, pode assim, tornar-se um fator positivo." ( $(32$ p.23).

\section{Longevidade e suas conseqüências para o indivíduo e para um envelhecimento saudável}

Sabemos que a expectativa de vida e a qualidade de vida não dependem somente de condições físicas ou biológicas. Fatores sociais, psicológicos e ambientais também são importantes. Não só o nível da medicina curativa afeta a expectativa 
de vida, mas também, e num nível muito mais elevado, o conhecimento e a aceitação de medidas preventivas. Daí que, muito mais atenção deve ser dada à prevenção e à reabilitação. Os indivíduos estão vivendo mais. Na verdade, é uma tarefa para todos, mas também para a sociedade, fazer todo o possível para prolongar o período de vida ativo e saudável ao invés de simplesmente retardar a hora da morte.

O nosso objetivo é alcançar um estado de bem-estar psicológico até à idade avançada. Com a "sociedade em estado de envelhecimento", os problemas de saúde tomam uma nova forma. Manter-se saudável se torna o objetivo central da vida e, na verdade, uma tarefa para todos. Deve-se evitar os riscos e deve-se dar atenção a uma nutrição saudável, abstenção de drogas, nicotina e álcool e prover atividades físicas e mentais. Mas também é necessário, mesmo nos primeiros anos de vida, desenvolver a habilidade em lidar com o estresse e dificuldades.

O modelo clássico da OMS (Organização Mundial de Saúde) enfatiza os aspectos médicos da mortalidade, morbidez e incapacidade física. O novo modelo OMS é interdisciplinar e também está integrando as ciências sociais. O envelhecimento saudável é influenciado tanto em nível individual e pessoal, como em nível de sistema e meio ambiente. O envelhecimento não é somente um processo biológico-fisiológico e psicológico. $\mathrm{O}$ envelhecimento é também um destino social.

Na Alemanha Ocidental, Rene Schubert, professor de Medicina Interna e antigo aluno de Max Bürger e, desde 1972 professor de Geriatria na Universidade de Erlangen (junto com representantes de outras áreas da medicina, mas também junto com a psicologia e a sociologia) fundou, em 1967, a Sociedade Alemã de Gerontologia. Foi uma organização interdisciplinar. Schubert enfatizou muito este fato, por exemplo, afirmando, já há 30 anos atrás: a Gerontologia tem, certamente, que ter como foco a $\mathrm{Ge}$ riatria, mas deve ter o apoio de psicólogos, sociólogos, padres, arquitetos, e por fim e não menos importante, de políticos que devem auxiliar a implementar planos bem elaborados. 
Precisamos de medidas de intervenção: $O$ que pode ser feito para assegurar uma alta qualidade de vida na velhice? São necessárias medidas de otimização, prevenção, reabilitação e manutenção.

Não existe nenhuma dúvida: higiene, cuidados preventivos e um bom sistema de assistência à saúde geral são essenciais para isso. Mas também é importante otimizar o desenvolvimento do indivíduo, estimulando-o a atividades físicas, mentais e sociais desde a infância e adolescência.

Existem muitos estudos que confirmam que atividade física é um pré-requisito para um envelhecimento com sucesso. Mudanças físicas determinadas pela idade, tais como a incapacitação funcional dos órgãos, modificações nos sistemas motor e muscular, bem como modificações nos órgãos respiratórios (que, é claro, dependendo do indivíduo, podem aparecer em qualquer idade), são semelhantes aos efeitos da falta de exercício. $\mathrm{O}$ indivíduo jovem fisicamente inativo parece velho, exatamente como o indivíduo velho e ativo parece jovem. Existe uma certa verdade no slogan : "os esportes e a atividade física ajudam a ficar nos 40 por 20 anos", ou “50 anos por 30”. A atividade física também afeta o bem-estar psicológico no que diz respeito às habilidades, bem-estar pessoal, habilidades (skills) sociais e auto-estima.

A atividade mental também é um pré-requisito para o envelhecimento com sucesso. Muitos estudos, especialmente estudos longitudinais, descobriram que indivíduos mentalmente mais ativos, com um QI mais alto, com uma maior gama de interesses, uma perspectiva de futuro mais distante, e um grande número de contatos sociais, alcançam a velhice com um maior sentimento de bem-estar psico-físico. Ficou estabelecido que a atividade cognitiva é essencial para um envelhecimento saudável. As pessoas idosas deveriam receber tarefas mentais; se deveria fornecer-lhes novas informações e serem desafiados a atividades mentais. A redução da atividade mental pode acelerar o processo de envelhecimento. 
Isto também pode funcionar ao contrário: o desafio mental pode fazer com que as pessoas mais velhas ajam espontaneamente, de uma maneira semelhante àquela que se espera dos indivíduos mais jovens.

A motivação para as atividades mentais, físicas e sociais tem de ser aumentada. Uma variedade de atividades deve ser oferecida também pela comunidade e a sociedade, a fim de tornar esses objetivos atraentes para cada um dos indivíduos. $\mathrm{E}$ muitas barreiras da nossa sociedade (como a imagem negativa da sociedade em relação ao idoso, condições ambientais, como condições de transporte desfavoráveis, etc.) devem ser reduzidas ou eliminadas totalmente.

Todavia, o envelhecimento é um processo que se desenrola ao longo da vida. O papel importante que desempenham as atividades físicas e mentais deve se tornar claro desde a infância. Também se faz necessário manter um alto grau de atividade física, social e mental nos homens e mulheres durante a idade adulta. Um outro tipo de prevenção que deve ser mencionado aqui, é o desenvolvimento das estratégias de superação (coping-strategies). O indivíduo deve aprender, no decorrer de toda a sua vida, como lidar com situações difíceis, com crises e superar tais situações (Lehr, 1985; Thomae, 1983).

\section{Correlação entre envelhecimento saudável e longevidade}

A partir de resultados de estudos internacionais e de muitas outras descobertas a partir do nosso estudo BOLSA, podemos concluir que nenhuma única variável pode, independentemente, explicar a longevidade e o envelhecimento saudável. Tão influentes quanto possam ser os fatores físicos e genéticos e, enfatizando os fatores biológicos, não são suficientes para explicar a longevidade. 


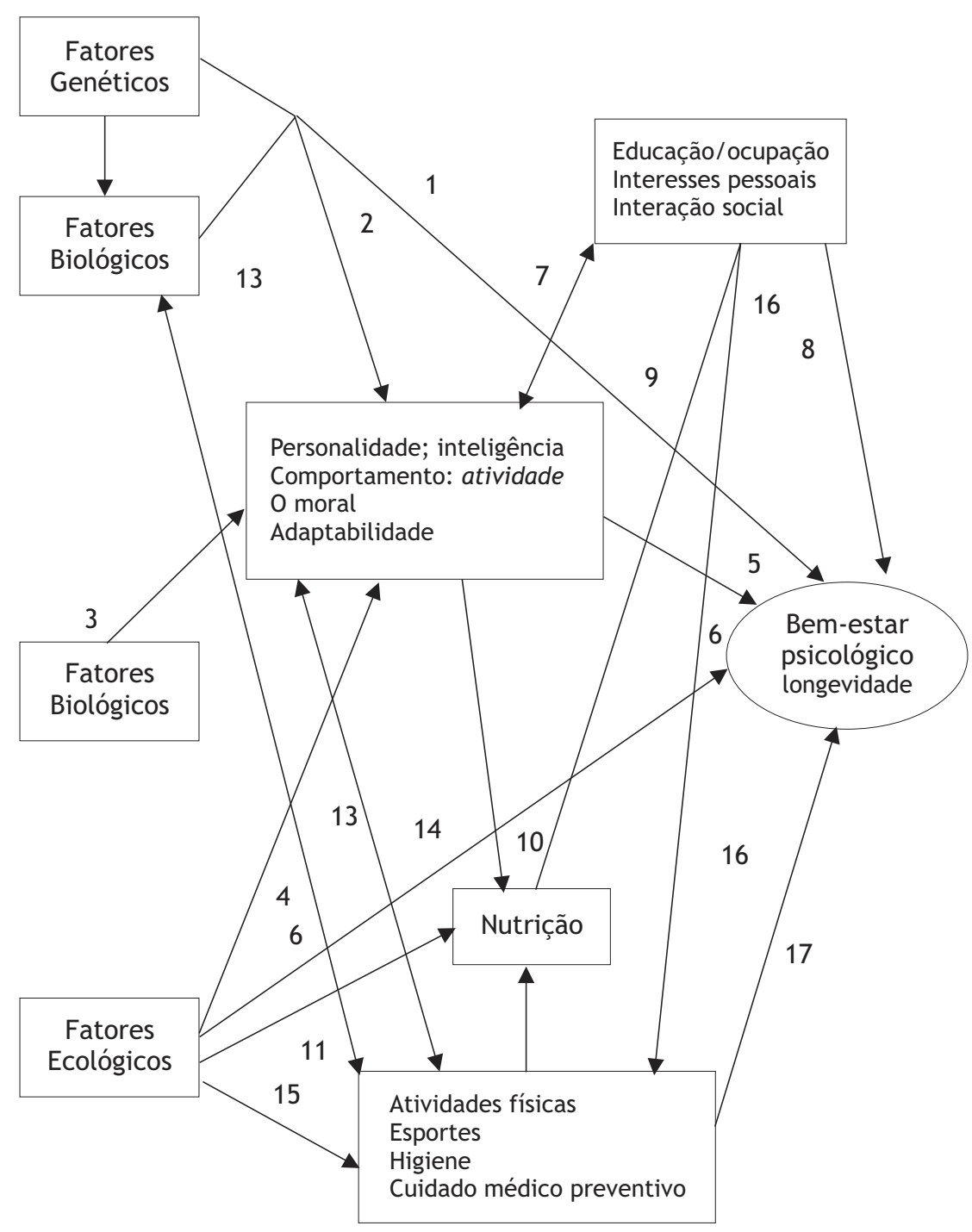

Figura 1. Correlação do bem-estar psicofísico 
Os resultados da pesquisa internacional sobre longevidade aponta um número de relações interessantes. Contudo, considerando-se o atual estado da pesquisa, ainda é prematuro chegar a teorias ou mesmo relações com força de lei, que possam estar relacionadas com a expectativa de vida longa. Em especial, deve-se enfatizar que, uma série de fatores que possivelmente possam influenciar o aumento da expectativa de vida interagem entre si. Essa interação aparentemente leva a uma complexa rede causal recíproca.

Um possível modelo para estas influências interativas sobre a longevidade pode ser visto na Figura.

Fatores genéticos, físicos e biológicos podem ser vistos como tendo uma influência direta sobre a longevidade (1) e também sobre o desenvolvimento da personalidade ( 2 ) do indivíduo (personalidade, inteligência, atividade, o moral, adaptabilidade, autoestima, etc.). Além do mais, o desenvolvimento da personalidade é determinado pelos processos de socialização: métodos de como criar os filhos, os professores, as pessoas próximas (significant others) e o meio ambiente social em geral, determinam as experiências e o comportamento do indivíduo; os fatores históricos também desempenham um papel neste processo de socialização (3). Além disso, determinantes ecológicos tais como meio ambiente físico, o viver em áreas urbanas ou rurais com seus estímulos específicos, e as condições climáticas têm um impacto sobre o desenvolvimento da personalidade (4). Muitos estudos identificam a existência de relações diretas entre a personalidade e a longevidade (5). Correlações entre fatores ecológicos e longevidade (6) também são referidas com freqüência nos estudos sobre os centenários. As variáveis de personalidade, por outro lado, têm um impacto sobre a escolaridade e o treinamento ocupacional, sobre as atividades ocupacionais e, assim, sobre o status sócio-econômico (7). A correlação entre status social e longevidade (8) foi determinada, principalmente, a partir de estatísticas de vida e análises demográficas, bem como por estudos longitudinais de acompanhamento, encontrando um aumento na expectativa de vida dos indivíduos com status sócio-econômico alto. 
O status social (9) e a personalidade (10) assim como os fatores ecológicos (11) influenciam os hábitos alimentares. Além do mais, afirma-se que existe uma correlação direta entre nutrição e longevidade (12). O papel da nutrição para a diabetes em relação à idade, e os aspectos nutricionais da arteriosclerose e enfarte devem ser mencionadas aqui.

Chegou-se à conclusão de que os fatores genéticos e biológicos (13), personalidade (14), variáveis ecológicas (15), e status sócioeconômico (16) influenciam as atividades físicas e os esportes, cuidado médico preventivo e a higiene. As correlações de todas estas variáveis com a longevidade (17) também foram comprovadas.

O nosso modelo, de forma alguma, inclui todas as variáveis que possam influenciar a longevidade. Simplesmente tem como objetivo estimular outros estudos empíricos e dar estímulo a futuras modificações, elaboração e diferenciação (veja Lehr 1982).

A análise dos dados do Estudo Longitudinal de Bonn sobre a Velhice assinala muitas descobertas no que diz respeito às correlações entre longevidade e envelhecimento saudável, o que leva a uma importante conclusão: nenhuma única variável pode, por si só, explicar a longevidade e o bem-estar na velhice. Tão influentes quanto possam ser os fatores genéticos e físicos, e enfatizandose os fatores biológicos, não podem ser vistos como os únicos determinantes da longevidade. O que deve receber atenção primordial é o fato de que uma série de fatores psicológicos, como socialização, personalidade, estímulo ambiental, status social e estilos de vida especiais, que, possivelmente, podem influenciar no aumento da expectativa de vida, interagem entre si e parecem fazer parte de uma rede causal recíproca e complexa.

Cientistas de todas as disciplinas e faculdades têm discutido esta questão da longevidade combinada com um estado de bem-estar psico-físico. Sabemos que o envelhecimento é afetado de modo diferente, por herança biológica, comportamentos do indivíduo, e por uma grande gama de fatores sociais, meio ambiente, culturais e políticos. O envelhecimento saudável é o resultado de um processo ao longo da vida. Sabemos que uma série de influências na infância, adolescência, início e meio da vida adul- 
ta, mas também a atual situação de vida do idoso são determinantes no processo de envelhecimento e de bem-estar na velhice. A cooperação interdisciplinar é necessária, para a qual a biologia do envelhecimento, geriatria, ciências do comportamento e ciências sociais devem contribuir. O envelhecimento saudável é um desafio para todos os gerontólogos, um desafio para os cientistas de muitas disciplinas, e um desafio também para os políticos.

\section{Observações de conclusão: uma política para o idoso}

Uma política para o idoso tem de basear-se nos três itens principais:

- o primeiro é manter e aumentar as competências do idoso a fim de prevenir a dependência e assegurar um envelhecimento saudável;

- o segundo é a extensão e melhoria das medidas de reabilitação a fim de recapacitar o idoso a uma vida independente. É necessário promover programas de reabilitação para o idoso;

- o terceiro é resolver os problemas do idoso frágil e dependente, resolver o problema do cuidado.

Mas uma política voltada para o idoso é mais do que uma política de cuidado (care) ou uma política de sistemas de aposentadorias. E a política do cuidado tem de também incluir outros aspectos além dos financeiros.

A política para o idoso é a política do estar saudável. Contudo, envelhecimento saudável não deve ser definido somente pela ausência de doenças, ou pelo bem-estar psico-social e psico-fisico (como a definição da OMS), mas também inclui a habilidade em superar adequadamente situações difíceis, problemas de saúde, limitações e deficiências físicas, e continuar aproveitando a vida.

A atitude da sociedade em relação aos velhos também é um fator decisivo para o bem-estar físico e psicológico na velhice. É, conseqüentemente, um motivo de preocupação o fato de que, em muitos países, o problema da velhice seja considerado hoje, so- 
mente em termos de necessidade de cuidado. Já, há quinze anos atrás, especialistas internacionais em gerontologia (médicos, psicólogos, sociólogos e cientistas de outros campos) numa comunicação à Assembléia Mundial das Nações Unidas sobre o Envelhecimento (Viena, agosto de 1982) observaram que as pesquisas mostravam claramente que: "A maioria dos idosos gozam de razoável saúde e são, dentro de suas limitações, capazes de atividades produtivas. Muitas políticas governamentais, no entanto, não reconhecem as capacidades físicas, intelectuais e emocionais, e as necessidades dos idosos, ao contrário, enfatizam o lado negativo e as deficiências da idade. Esta posição negativa influencia a saúde física e a competência mental e produz dependência. A sociedade deve reconhecer o idoso como uma fonte da qual a própria sociedade e o idoso podem se beneficiar."

Em 1985, Robert N. Butler enfatizava: “...a participação de pessoas mais velhas enriquece as sociedades econômica, cultural e espiritualmente". A saúde e a produtividade estão intimamente ligadas. A perda de uma delas pode levar à perda da outra e assim, levar ao declínio das habilidades mentais, psicológicas e físicas, à incompetência e, finalmente, à dependência - enquanto que a produtividade, a participação, a responsabilidade e o sentimento de ser necessário, têm um efeito favorável sobre a saúde.

Temos de “(...) reconhecer que a saúde e a produtividade são condições que interagem. A pessoa humana que não é produtiva tem risco mais alto de doenças e dependência econômica; e a pessoa doente é limitada na sua produtividade, conseqüentemente, corre um risco maior de dependência." (p. 12).

Existem muitos estudos que confirmam que a atividade física bem como a atividade mental são condições para um envelhecimento bem sucedido. De acordo com muitos estudos, especialmente os longitudinais, os indivíduos que estão alcançando uma vida longa mais compensadora são os que permaneceram mentalmente mais ativos, desenvolveram uma maior gama de interesses, têm uma perspectiva maior de tempo de vida futura e têm um maior número de contatos sociais. Foi provado também que a atividade cognitiva é essencial para o envelhecimento saudável. 
A motivação para atividades físicas, mentais e sociais deveria ser reforçada. Uma gama de opções deve ser oferecida pela sociedade a fim de tornar esses objetivos mais atraentes para cada indivíduo. E muitas barreiras que são colocadas pela sociedade (especialmente no que diz respeito ao meio ambiente ou ao transporte) devem ser reduzidas ou eliminadas totalmente.

Na nossa sociedade, e mesmo entre os médicos, enfermeiros e funcionários de hospitais, existem muitos estereótipos negativos a respeito do idoso. Muitas pessoas vêem o declínio das habilidades na velhice como inevitáveis e irreversíveis. Neste contexto, deve-se lembrar que as expectativas dos outros determinarão o auto-conceito e, conseqüentemente, o comportamento do indivíduo. Devido a este estereótipo negativo, o idoso é, muitas vezes, um caso problema da sociedade. Se quisermos lidar com o idoso de forma adequada, nós temos de revisar a imagem que dele fazemos.

Velhice, longevidade não devem ser vistas como um problema mas como uma oportunidade e um desafio - um desafio para todos: para o indivíduo em fase de envelhecimento, para a sua família e para a nossa sociedade. Não devemos somente perguntar sobre os problemas e deficiências do envelhecimento e da velhice! Envelhecimento é um processo de desenvolvimento que começa com o nascimento (com a concepção) e vai até a morte! E nós temos de perguntar - e temos de abrir os nossos olhos, e temos de iniciar pesquisas sobre - as competências e os novos potenciais do idoso, também das pessoas muito velhas. E, tenho certeza, encontraremos novos potenciais - mesmo no grupo de idosos frágeis e incapacitados fisicamente.

\section{Referências bibliográficas}

1 BÄCKER, G.; NAEGELE, G. Alternde Gesellschaft und Erwerbstätigkeit. Köln, Bund Verlag, 1993

2 BUTLER, R. N.; GLEASON, H.P. (Orgs.) Productive Aging - Enhancing Vitality. In Later Life, New York, Springer Publ. Comp., 1985.

3 FRIIS, H. Opening Plenary Session of the II European Congress of Gerontology, Madrid, 11- 14 Sept. 1991. 
4 HEARNSHAW, L. S. Age and Work. Age and Ageing, n. 1, p. 81-87, 1972

5 HÖHN. Das Übergewicht der Alten - ein Wohlstandsphänomen. ln: Deutschen Gesellschaft für die Vereinten Nationen, Weltbevölkerung und Entwicklung. Bonn 1993

6 INFRATEST. Hilfe-und Pflegebedarf in Deutschland 1991: Möglichkeiten und Grenzen selbständiger Lebensführung, München. Infratest, 1992

7 JHNSON;ZIMMERMANN. Labor Markets in an Aging Europe. London, 1993

8 LEHR, Ursula. Socio-psychological Correlates of Longevity. Annual Review of Gerontology and Geriatries, n.3, 102-147, 1982

9 LEHR, Ursula \& THOMAE, Hans (Orgs). Formen seelischen Alterns. Ergebnisse der Bonner Gemtologischen Längsschnittstudie (BOLSA). Stuttgart, Enke, 1987.

10 SCHAEFER, Hans. Die Frau im Alter als Problem der Sozialmedizin. In LEHR, U. (Org.) Seniorinnen - Zur Situation der diteren Frau, Darmstadt, Steinkopff, 1978, p. 5460.

11 STAGNER, R. Aging in Industry. In: BIRREN, JE.; SCHAIE, W. K. (Orgs.) Handbook of the Psychology of Aging. 2 ed. New York, Van Nostrand, 1985 p. 789-817.

12 STERNS, H. L.; ALEXANDER, R. A. Industrial Gerontology: The aging individual and work. Annual Review of Gerontalogy and Geriatrics, n. 7, p. 243 264, 1987.

13 TEO, Peggy. Aging Trends: Aging in Singapore, 1996

14 THOMAE, H. Alternstile und Altersschicksale: Ein Beitrag zur Differenticilen Gerontologie. Bern, Huber, 1983 